\title{
Plasmacytoid urothelial carcinoma (PUC): Imaging features with histopathological correlation
}

\author{
Andrew D. Chung, MD; Nicola Schieda, MD; Trevor A. Flood, MD; Ilias Cagiannos, MD, Kien T. Mai, MD; \\ Shawn Malone, MD, ${ }^{4}$ Christopher Morash, MD, ${ }^{3}$ Shaheed W. Hakim, MD, ${ }^{2}$ Rodney H. Breau, MD
}

'Department of Medical Imaging; ${ }^{2}$ Department of Anatomical Pathology; ${ }^{3}$ Department of Surgery, Division of Urology; ${ }^{4}$ Department of Radiation Oncology; The Ottawa Hospital, University of Ottawa, Ottawa, ON, Canada

Cite as: Can Urol Assoc J 2017;11(1-2):E50-7. http://dx.doi.org/10.5489/cuaj.3789 Published online January 12, 2017

\section{Abstract}

Introduction: Plasmacytoid urothelial carcinoma (PUC) is a highgrade variant of conventional urothelial cell carcinoma. This study is the first to describe the imaging findings of PUC, which are previously unreported, using clinical and histopathological correlation. Methods: With internal review board approval, we identified 22 consecutive patients with PUC from 2007-2014. Clinical parameters, including age, gender, therapy, surgical margins, and longterm outcome, were recorded. Baseline imaging was reviewed by an abdominal radiologist who evaluated for tumour detectability/location/morphology, local staging, and presence/location of metastases. Pelvic peritoneal spread of tumour (defined as $>5 \mathrm{~mm}$ thick soft tissue spreading along fascial planes) was also evaluated. Followup imaging was reviewed for presence of local recurrence or metastases.

Results: Median age at presentation was 74 years (range 51-86), with only three female patients. Imaging features of the primary tumour in this study were not unique for PUC. Muscle-invasive disease was present on pathology in 19/22 (86\%) of tumours, with distant metastases in $2 / 22(9 \%)$ at baseline imaging. Pelvic peritoneal spread of tumour was radiologically present in 4/20 $(20 \%)$ at baseline. During followup, recurrent/residual tumour was documented in 16/22 (73\%) patients and 7/16 (44\%) patients eventually developed distant metastases. Median time to disease recurrence in patients who underwent curative surgery was three months (range 0-19).

Conclusions: PUC is an aggressive variant of urothelial carcinoma with poor prognosis. Pelvic peritoneal spread of tumour as thick sheets extending along fascial planes may represent a characteristic imaging finding of locally advanced PUC.

\section{Introduction}

Bladder cancer represents the fourth most common malignancy in men and eighth most common malignancy in women. The majority of bladder neoplasms are of urothelial origin. ${ }^{1,2}$ Plasmacytoid urothelial carcinoma (PUC) is a rare variant of urothelial carcinoma. ${ }^{3} \mathrm{PUC}$ was first described by Sahin et al and Zuckerberg et al, histologically resembling plasma cells with a dyscohesive pattern, abundant eosinophilic cytoplasm, and eccentric nuclei. ${ }^{4,5} \mathrm{PUC}$ tends to extensively involve the bladder wall and frequently extends into the perivesical soft tissues. ${ }^{6-9}$ This aggressive pattern of invasion results in high risk of local recurrence, metastatic disease, and cancer-related death..$^{10-12}$

Studies describing PUC are limited to case series. ${ }^{10,12}$ Diagnosis of PUC is histologically challenging because it may resemble other tumours. PUC must be distinguished from other malignancies, such as plasmacytoma, signet ring adenocarcinoma, and metastatic breast or gastric cancer. ${ }^{13,14}$ PUC is commonly locally advanced at presentation..$^{10-12}$ After attempts at definitive local therapy, both pelvic recurrence and metastatic disease are common. Metastases from PUC have a predilection for peritoneal spread, occurring in $33-68 \%$ of patients. ${ }^{10,11}$ Furthermore, PUC has been shown to follow an unusual, but characteristic pattern of local spread histologically, with extension along pelvic fascial planes to involve perivesical, perirectal, and periureteric soft tissues. ${ }^{15}$

Patients with local fascial spread are unlikely to be cured with radical resection. Therefore, identification of fascial spread on imaging may allow some patients to avoid the morbidity associated with surgery. To our knowledge, the radiological appearance of PUC has never been previously described in the literature. The purpose of this study was to describe the features of PUC on computed tomography (CT) and magnetic resonance imaging (MRI) at baseline and during followup, with clinical and histopathological correlation.

\section{Methods}

With research ethics board approval, a retrospective search of the electronic medical database at our institution identified 22 patients with PUC from December 2007-April 2014 (Fig. 1). Patient medical records were reviewed to retrieve patient demographics and clinical variables, including sex, age at 


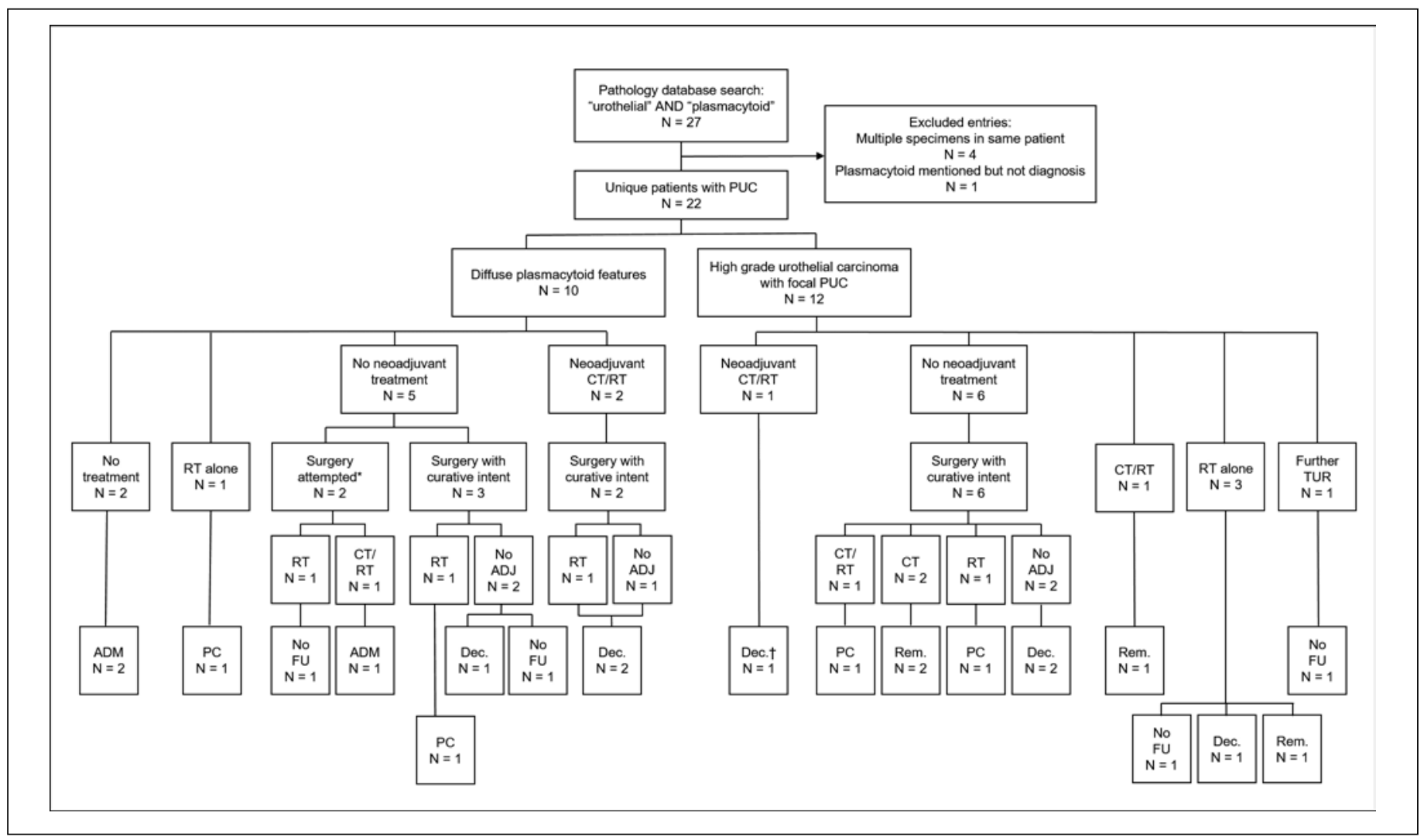

Fig. 1. Inclusion criteria and clinical pathway for all 22 patients. *Planned for curative surgery, but aborted due to high burden of disease intraoperatively; ${ }^{\dagger}$ planned for curative surgery, but progressed with metastatic disease during neoadjuvant treatment. ADJ: adjuvant therapy; ADM: admitted to another institution at last point of contact; CT: chemotherapy; Dec: deceased; FU: followup; PC: receiving palliative care at last point of contact; Rem: clinical remission; RT: radiotherapy; TUR: transurethral resection.

diagnosis, imaging studies performed, stage of disease at diagnosis, surgical treatment, surgical margin status, disease recurrence, metastatic disease, and cancer-related death. Baseline imaging was defined as a staging CT or MRI performed prior to initiation of treatment (surgery, chemotherapy, or radiation therapy), not including transurethral resection (TUR) or biopsy.

\section{Imaging technique}

CT studies were performed using a variety of imaging protocols, which consisted of both unenhanced (NECT) and contrast-enhanced (CECT) studies. The CT imaging protocols used are described in greater detail in Appendix A. MRI was performed using a clinical 1.5 Tesla MR scanner in all patients. Appendix B provides a detailed description of the MRI protocol used at our institution.

\section{Image analysis}

Baseline CT and MRI studies were reviewed by a radiology resident $(\mathrm{AC})$ and a fellowship-trained genitourinary radiologist with 10 years of experience in genitourinary (GU) imaging (NS). The radiologist was blinded to the original interpretation, clinical information, and pathological/surgical findings of each patient. The following imaging findings were recorded: visibility of primary tumour, tumour characteristics (mass or bladder wall thickening), calcification, and location. The presence or absence of metastatic lymphadenopathy (defined as $>1.0 \mathrm{~cm}$ short axis diameter) and other sites of metastatic disease wi e documented. Assessment for pelvic peritoneal spread of tumour was defined as a binary outcome and was considered present when there was thick $(>5 \mathrm{~mm}$ ) soft tissue spreading along pelvic fascial compartments (e.g., mesorectal fascia, pelvic sidewall). For MRI studies, tumour staging and presence of pelvic peritoneal spread were also assessed. For patients who had followup imaging available, the presence of residual/locally recurrent or distant metastases was recorded.

\section{Results}

Twenty-two patients with PUC were identified (Fig. 1), of which 10/22 (45\%) showed diffuse plasmacytoid features on histopathology and 12/22 (55\%) showed foci of PUC on a background of high-grade urothelial carcinoma. Table 1 shows the characteristics of all 22 patients at presentation. 


\begin{tabular}{lc}
\hline Table 1. Characteristics of all 22 patients at presentation \\
\hline Median age (range) & $74(51-86)$ \\
No. male (\%) & $19(86)$ \\
No. female (\%) & $3(14)$ \\
Primary tumour (\%) & \\
$\quad$ Urinary bladder & $20(91)$ \\
Renal pelvis & $2(9)$ \\
Baseline imaging (\%) & \\
Abdominopelvic imaging & $22(100)$ \\
$\quad$ CT & $22(100)$ \\
$\quad$ MRI & $8(36)$ \\
Thoracic imaging & $21(100)$ \\
$\quad$ Plain film & $9(41)$ \\
CT & $12(55)$ \\
Pathology (\%) & $10(45)$ \\
Diffuse plasmacytoid features & $12(55)$ \\
High-grade urothelial carcinoma with focal PUC & $19(86)$ \\
Muscle invasive (pT2) disease (\%0 & \\
\hline CT: computed tomography; MRl: magnetic resonance imaging; PUC: plasmacytoid \\
urothelial carcinoma.
\end{tabular}

The primary site of disease was the urinary bladder in 20/22 (91\%) patients and the renal pelvis in $2 / 22(9 \%)$ patients. Pathological diagnosis of PUC was made at time of TUR in 15 patients. Five patients had a known diagnosis of muscleinvasive bladder cancer on TUR, with pathological diagnosis of PUC made at time of cystectomy or open excisional biopsy. PUC was diagnosed at nephroureterectomy in two patients. From the 15 patients who underwent TUR, five patients underwent subsequent cystectomy, two further TUR, and one exploratory laparotomy. Therefore, half (11/22) of patients underwent radical surgery (cystectomy or nephroureterectomy) with intent to cure (Fig. 1). Two of these patients (18\%) underwent neoadjuvant chemotherapy with cisplatin/gemcitabine and radiotherapy prior to radical surgery. One patient underwent neoadjuvant chemoradiation, but did not proceed to surgery due to interval development of metastatic disease. At surgical pathology, 19/22 (86\%) tumours demonstrated muscle invasion ( $\geq \mathrm{pT} 2$ disease). In the 11 patients who underwent radical surgery, $9 / 11(82 \%)$ had pT3 disease or greater, and surgical margins were positive in 5/11 (45\%) (Table 2).
Baseline abdominopelvic CT was available in all 22 patients, with MRI available in eight. Twenty-one patients had baseline chest imaging. Table 3 summarizes the findings at baseline imaging. Pelvic peritoneal spread as thick sheets of tumour was radiologically present in $4 / 20(20 \%)$ patients with bladder tumours. Two of these patients underwent radical cystoprostatectomy after $\mathrm{CT}$, which pathologically confirmed extensive fascial spread and positive surgical margins.

The primary bladder tumour was considered definitely visible in all six patients who underwent baseline MRI and detrusor muscle invasion was considered present in $4 / 6$ patients (Fig. 2), with a sensitivity of $80 \%$ compared to surgical pathology. Pelvic peritoneal spread of tumour was identified in 3/6 (50\%) patients (also detectable on CT) with thick hypointense sheets of tissue spreading diffusely along the pelvic sidewall and perirectal fascial planes on T2-weighted (W) MRI (Figs. 3, 4). At baseline imaging, 2/22 (9\%) patients had distant metastatic disease to lung (1/22), liver $(1 / 22)$, and bone (1/22).

Clinical followup was available in all 22 patients, with followup imaging in 16/22 (73\%). Median followup time from diagnosis was 338 days (range 4-1640). Of the patients who underwent surgery with intent to cure, $54 \%$ received adjuvant therapy with radiotherapy (3/11), chemotherapy $(2 / 11)$, or combined chemoradiation (1/11). Of patients who did not receive radical surgery, $8 / 11(73 \%)$ were treated with combination of radiation and/or chemotherapy for local control or palliation (Fig. 1).

Residual or recurrent disease was present in 16/22 (73\%) during followup, established by imaging studies or cystoscopy. This includes 8/11 (73\%) patients who underwent surgery with curative intent, with a median time to relapse of three months (range 0-19). In three patients, metastatic disease was discovered in the perioperative period. On followup imaging, 7/16 (44\%) patients developed distant metastases. The peritoneum and retroperitoneal lymph nodes were the most common sites of metastases, present in 5/16 (31\%) and $4 / 16$ (25\%) of patients, respectively (Fig. 5). One patient developed liver, bone, and adrenal metastases.

\begin{tabular}{|c|c|c|c|c|c|c|}
\hline Age & Gender & pT stage & Margins & Lymph nodes & Plasmacytoid features & Clinical followup (mos) \\
\hline 61 & $\mathrm{M}$ & pT4a & - & - & Focal & Clinical remission (27) \\
\hline 75 & M & pT4a & - & + & Diffuse & Lost to followup \\
\hline 65 & $\mathrm{~F}$ & pT3 & - & + & Focal & Palliative (15) \\
\hline 60 & M & pT3b & + & - & Diffuse & Palliative (20) \\
\hline 62 & M & pT4a & + & Not evaluated & Diffuse & Deceased (9) \\
\hline 77 & M & pT3 & + & + & Focal & Deceased (0) \\
\hline 51 & M & pT3 & - & + & Focal & Clinical remission (55) \\
\hline 73 & M & PT2b & - & - & Diffuse & Deceased (18) \\
\hline 66 & M & pT3b & + & - & Focal & Palliative (16) \\
\hline 74 & M & pT2 & - & - & Focal & Deceased (5) \\
\hline 65 & M & pT4b & + & Not evaluated & Diffuse & Deceased (9) \\
\hline
\end{tabular}




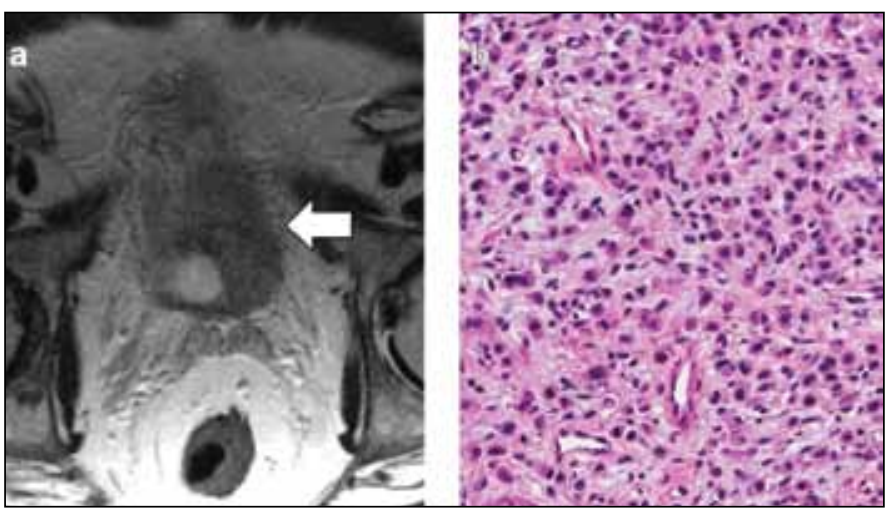

Fig. 2. 75-year-old male with muscle-invasive plasmacytoid urothelial carcinoma (PUC) who underwent preoperative staging magnetic resonance imaging. (a) Axial T2-weighted turbo spin echo image demonstrates a mass centred on the left urinary bladder wall with infiltration into and through the detrusor muscle (arrow) consistent with known muscle-invasive disease; (b) pathological image demonstrating dyscohesive malignant urothelial cells diffusely invading the lamina propria. Cells have abundant eosinophilic cytoplasm with eccentrically located nuclei, typical of PUC.

At the time of this study, 4/22 (18\%) patients were alive and in clinical remission. All four patients in clinical remission demonstrated focal PUC, with generally favourable clinical and histopathological features (negative margins on cystectomy or non-muscle invasive disease on TUR), which are described in Table 4. No patients with diffuse PUC were alive or in clinical remission at last followup.

Seven patients (32\%) were deceased or palliative at their last point of contact. This included all patients who demonstrated local spread along the pelvic sidewall or perirectal fascia on initial or followup imaging $(n=4)$, peritoneal metastases $(n=5)$, or positive surgical margins at time of radical surgery $(n=5)$.

Fig. 3. 62-year-old male with muscle-invasive plasmacytoid urothelial carcinoma who underwent preoperative staging magnetic resonance imaging. (a) Axial and (b) sagittal T2-weighted turbo spin echoimages show residual bladder tumour (white arrow) with invasion of the seminal vesicles (arrowhead). There are ill-defined strands of low T2 signal intensity material within the pelvis, forming sheets of tissue, consistent with peritoneal spread of tumour (open arrows); (c) post-gadolinium axial T1W fat-suppressed gradient echo shows that these sheets of tissue demonstrate solid enhancement; (d) contrast-enhanced computed tomography performed earlier demonstrates corresponding appearance on computed tomography.

\section{Discussion}

PUC is a rare, high-grade variant of urothelial cell carcinoma with advanced local stage of disease at presentation and poor long-term prognosis. ${ }^{10-12}$ The imaging appearance of PUC has, to our knowledge, never been described. We evaluated the imaging findings of PUC at baseline and during followup after treatment using CT and MRI. Our study demonstrates good CT/MRI correlation for the characteristic form of pelvic peritoneal spread that typifies PUC at histopathology, with thick sheets of tissue extending along pelvic fascial planes.

The spread of PUC as thick discontinuous sheets of tissue in the pelvis, along the pelvic sidewalls and perirectal fascia, was present in approximately one-fifth of patients on imaging, and was confirmed pathologically at time of radical cystectomy in two patients. This appearance may be a distinguishing imaging finding of PUC, as a previous histopathological study demonstrated that PUC characteristically spreads as discontinuous sheets of tumour along fascial planes involving the perivesical, perirectal, and periureteric fascia. ${ }^{15}$ Future studies are required to validate this imaging finding in comparison to high-grade conventional
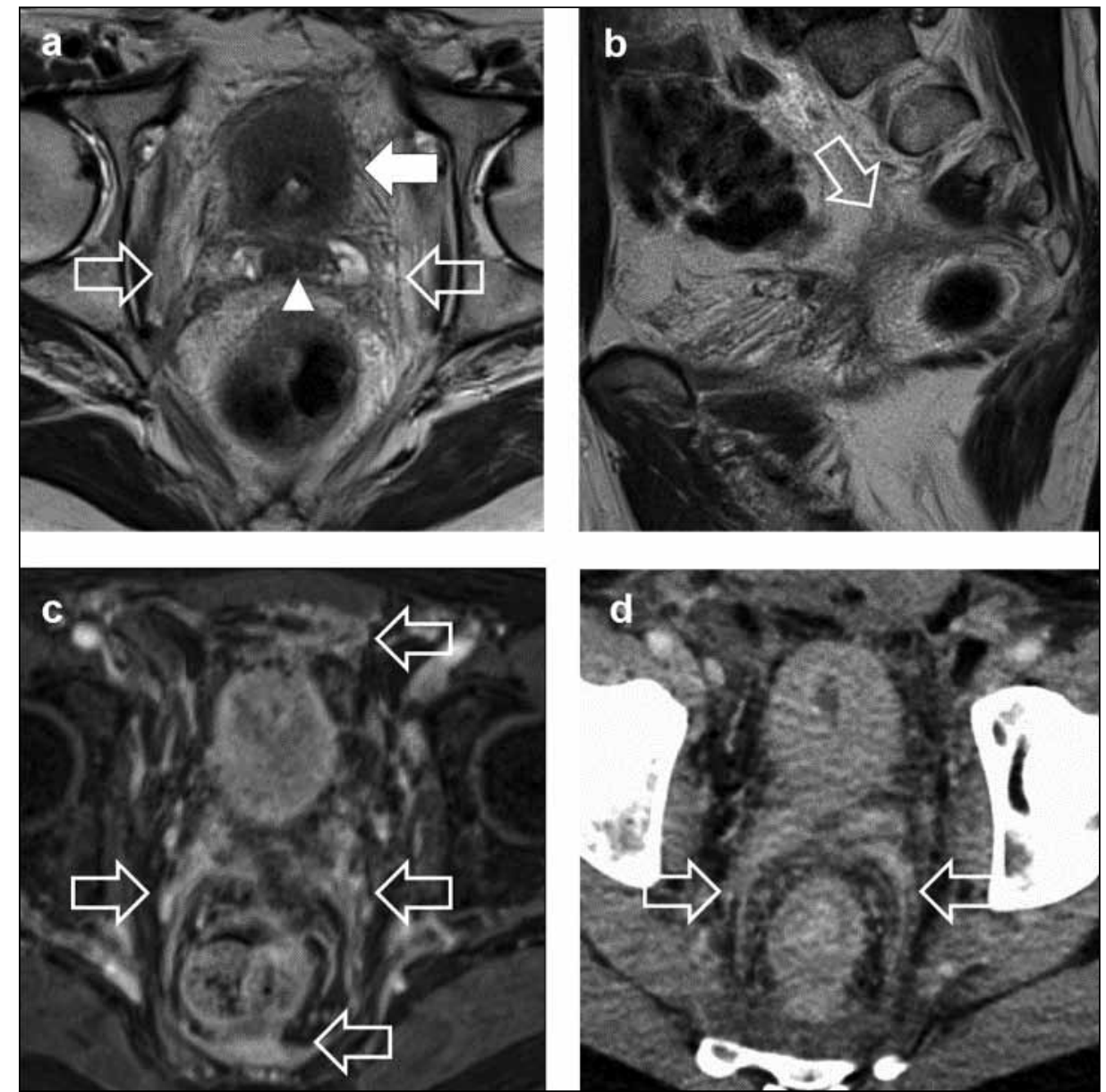

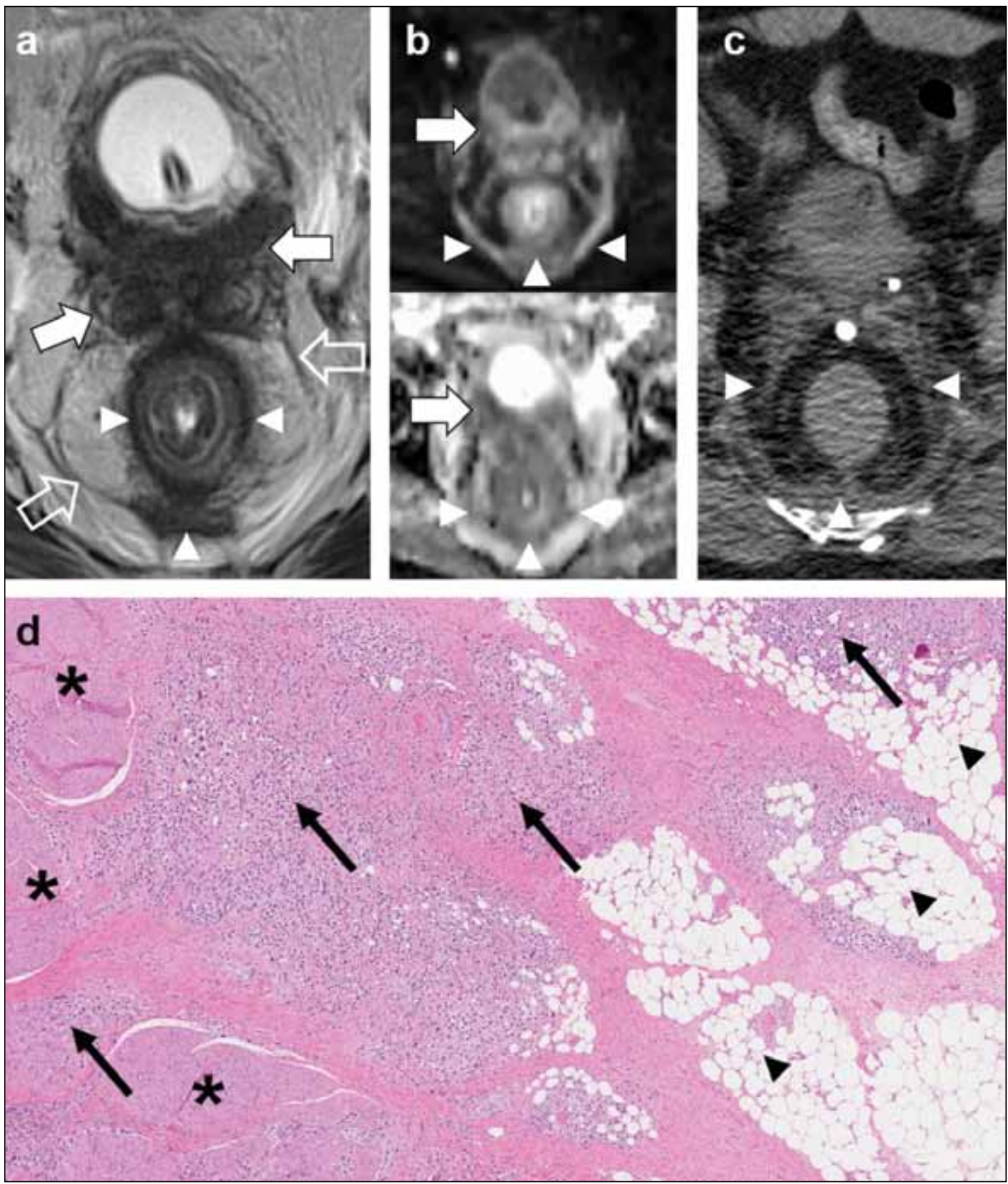

Fig. 4. 65-year-old male with plasmacytoid urothelial carcinoma (PUC) who underwent staging magnetic resonance imaging. Rectal examination at time of cystoscopy demonstrated pinpoint narrowing of the rectum, which was felt to be suspicious for synchronous rectal malignancy. (a) Axial T2-weighted turbo spin echo images show a heterogeneous low signal intensity (SI) mass invading through the posterior wall of the bladder into the seminal vesicles (white arrows). There are strands of low T2 SI in the pelvis (open arrows) with low T2 SI surrounding the rectum (arrowheads). Note that the normal rectal wall architecture is preserved; (b) axial b $1000 \mathrm{~mm}^{2} / \mathrm{sec}$ echo-planar images and axial apparent diffusion coefficient map show restricted diffusion in the bladder mass (white arrow) and in the rectal/perirectal soft tissues (arrowheads). Findings at pelvic exenteration confirmed locally advanced PUC. There was no rectal carcinoma; (c)contrast-enhanced computed tomography performed earlier demonstrates a similar pattern of spread, on retrospective review; (d) pathological image in a separate patient with PUC who underwent cystectomy, demonstrating typical pattern of spread with sheets of PUC cells (black arrows) invading the plane between the detrusor muscle (asterisk) and perivesical adipose tissue (black arrowheads). 

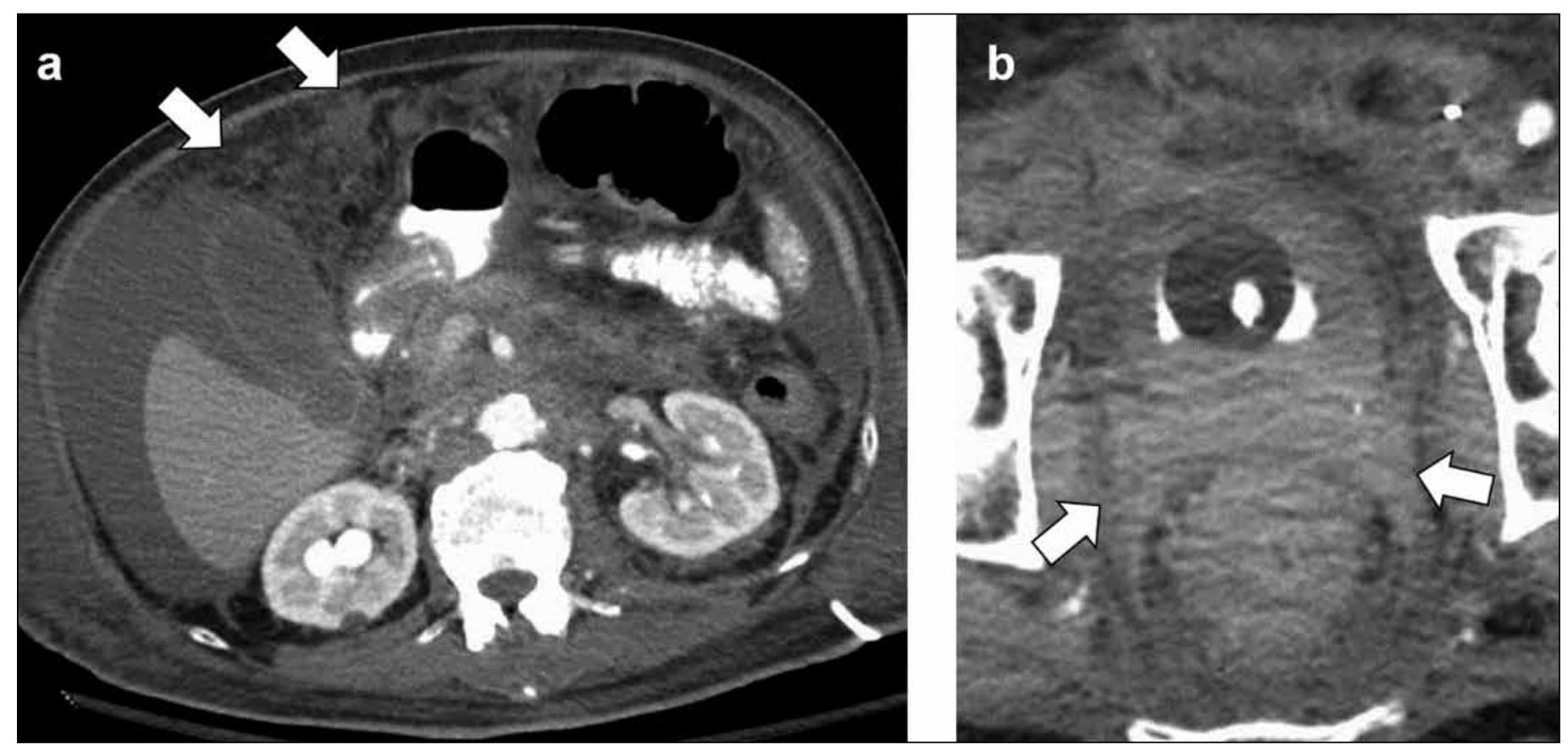

Fig 5. 75-year-old male with biopsy proven plasmacytoid urothelial carcinoma. (a) Axial contrast-enhanced computed tomography image through the upper abdomen obtained during the urographic phase of enhancement (split-bolus protocol) demonstrates large volume of malignant ascites with peritoneal carcinomatosis (arrows); (b) axial contrast-enhanced computed tomography image in the pelvis demonstrates diffuse bladder wall thickening with ill-defined soft tissue spreading into the pelvis with invasion of the seminal vesicles and prostate (arrows).

urothelial cell carcinomas, which if characteristic of PUC, may guide management.

The Canadian Urological Association (CUA) recognizes PUC as an aggressive bladder malignancy, with guidelines suggesting early cystectomy as treatment for non-muscle invasive disease; however, in a recent study by Keck et al, PUC demonstrated a poor prognosis when treated with cystectomy and cisplatin-based chemotherapeutics. ${ }^{16,17}$ These findings are similar to our institutional experience, in which PUC intraoperatively demonstrates a high burden of disease with extensive spread along pelvic fascial planes, with an extremely poor prognosis and significant challenges to any attempted surgical management. To our knowledge, no alternative chemotherapeutic regimen has been validated in this population; however, future therapy may be tailored to specific molecular markers, with human epidermal growth factor receptor type 2 (HER2) recently suggested as a potential therapeutic target in PUC. ${ }^{17,18}$

In our series, approximately half of patients who underwent radical cystectomy had a prior TUR in which a diagnosis of PUC was not suggested at histopathology. The majority of these patients demonstrated foci of PUC on a background of high-grade urothelial carcinoma, and failure to prospectively diagnose PUC may have been secondary to undersampling. While not always apparent on imaging, when present, pelvic peritoneal spread of tumour may offer valuable prognostic information and help to identify patients who are unlikely to benefit from surgery. Furthermore, if pelvic peritoneal spread

\begin{tabular}{|c|c|c|}
\hline CT $(n=22)$ & $\mathbf{n}$ & $\%$ \\
\hline \multicolumn{3}{|l|}{ Tumour visible } \\
\hline Bladder & $19 / 20$ & 95 \\
\hline Focal mass & $13 / 19$ & 68 \\
\hline Diffuse mural thickening & $6 / 19$ & 32 \\
\hline Renal pelvis $(n=2)$ & $1 / 2$ & 50 \\
\hline \multicolumn{3}{|l|}{ Local invasion } \\
\hline Ureter/uretovesical junction & 11 & 50 \\
\hline Prostate/seminal vesicles & 3 & 14 \\
\hline Vagina & 2 & 10 \\
\hline Renal vein & 1 & 5 \\
\hline Calcification & 4 & 20 \\
\hline Lymphadenopathy & 11 & 50 \\
\hline \multicolumn{3}{|l|}{ Visceral metastases } \\
\hline Lung & 1 & 5 \\
\hline Liver & 1 & 5 \\
\hline Bone & 1 & 5 \\
\hline $\begin{array}{l}\text { Tumour spread along pelvic fascial planes - } \\
\text { bladder tumour }\end{array}$ & $4 / 20$ & 20 \\
\hline \multicolumn{3}{|l|}{ MRI $(n=8)$} \\
\hline \multicolumn{3}{|l|}{ Tumour visible } \\
\hline Bladder & $6 / 6$ & 100 \\
\hline Renal pelvis & $1 / 2$ & 50 \\
\hline Muscle invasive & $4 / 6$ & 67 \\
\hline \multicolumn{3}{|l|}{ Local invasion } \\
\hline Prostate & 2 & 33 \\
\hline Renal vein & 1 & 17 \\
\hline $\begin{array}{l}\text { Confluent spread along pelvic fascial planes - } \\
\text { bladder tumour }\end{array}$ & $3 / 6$ & 50 \\
\hline
\end{tabular}




\begin{tabular}{|c|c|c|c|c|}
\hline Age & Gender & Treatment & Histopathology & Followup (mos) \\
\hline 61 & $\mathrm{M}$ & $\begin{array}{l}\text { Cystectomy; } \\
\text { adjuvant cisplatin/gemcitabine }\end{array}$ & $\begin{array}{l}\text { Focal plasmacytoid features; } \\
\text { pT4N0; margins negative }\end{array}$ & 27 \\
\hline 59 & M & $\begin{array}{l}\text { TUR; adjuvant radiotherapy (unsuitable for surgery due to } \\
\text { cardiac risk factors }\end{array}$ & $\begin{array}{l}\text { Focal plasmacytoid features; } \\
\text { non-muscle-invasive }\end{array}$ & 13 \\
\hline 79 & M & $\begin{array}{l}\text { TUR } \times 2 \text {; adjuvant cisplatin/gemcitabine and radiotherapy } \\
\text { (recurrence on second TUR, received chemoradiation as salvage }\end{array}$ & $\begin{array}{l}\text { Focal plasmacytoid features; } \\
\text { muscle-invasive }\end{array}$ & 10 \\
\hline 55 & M & $\begin{array}{c}\text { Cystectomy; } \\
\text { adjuvant cisplatin/gemcitabine }\end{array}$ & $\begin{array}{l}\text { Focal plasmacytoid features; } \\
\text { pT3N2; margins negative }\end{array}$ & 55 \\
\hline
\end{tabular}

of tumour is present on imaging, a diagnosis of PUC could be suggested if not already known. Nevertheless, prospective diagnosis of PUC remains a diagnostic challenge, with approximately half of patients who proceeded to radical cystectomy demonstrating no histopathological or imaging findings of PUC prior to surgery.

The primary tumour in PUC appears similar to that of conventional urothelial carcinoma. Similar to advanced pure urothelial carcinoma, the tumour was visible in $95 \%$ of patients. ${ }^{19-22}$ Conventional urothelial cell cancers can present as a focal mass and urinary bladder wall thickening, as was detected in our study. ${ }^{23-25}$ Detrusor muscle invasion was identified in the majority of patients in our study who underwent preoperative MRI; however, this finding can be observed in up to $54 \%$ of patients with conventional urothelial cell tumours. ${ }^{26}$

In this study, from patients who were treated surgically with curative intent, almost half of patients had positive surgical margins and over half developed locally recurrent tumour. Comparatively, for conventional urothelial carcinoma, rates of only $4-10 \%$ for positive surgical margins and $18-19 \%$ for local recurrence following radical cystectomy are reported in the literature. ${ }^{27-30}$ The relatively high risk of positive surgical margins and recurrent tumour reflect the aggressive nature of PUC. The high risk of peritoneal spread of disease is consistent with other PUC series $(33-68 \%){ }^{10,11,31,32}$

There are several limitations to our study. The retrospective nature of our study led to heterogeneity in imaging protocols used for CT and MRI, which limited our ability to assess for other imaging features, such as synchronous involvement of the urothelium and quantitative MR parameters. Additionally, we did not directly compare imaging features of PUC to a matched control sample of conventional urothelial cell tumours. Finally, duration of followup varied and our reported rate of metastatic disease and mortality may represent an underestimation because long-term followup was not available in all patients.

\section{Conclusion}

PUC is a rare, high-grade variant of urothelial carcinoma that often presents with locally advanced stage and has a poor long-term prognosis. Our results show good CT/MRI correlation for local spread of tumour along fascial planes in the pelvis, which has been reported as a characteristic histopathological finding of PUC. Future studies are required to compare the imaging findings described in our study to conventional urothelial cell carcinomas. If validated as a characteristic imaging finding in PUC, this pattern of disease may portend an extremely poor prognosis associated with significant challenges for treatment with curative intent.

Competing interests: Dr. Cagiannos has been an advisor for and received honoraria from AbbVie and Ferring. Dr. Morash has been an advisor for AbbVie, Astellas, Ferring, Janssen, and Sanofi; and has participated in a clinical trial for AbbVie (CRONOS II). The remaining authors report no competing personal or financial interests.

This paper has been peer-reviewed.

\section{References}

1. Guzzo TJ, Malkowicz SB, Vaughn DJ, et al. Chapter 16. Adult genitourinary cancer. In: Penn clinical manual of urology, 2nd edition, Philadelphia, PA: Saunders, 2014:505-8.

2. Wood DP. Chapter 80. Urothelial tumours of the bladder. In: Campbell-Walsh Urology, 10th edition, Philadelphia, PA: Saunders, 2012:2309-34.

3. Lopez-Beltran A, Sauter G, Gasser T, et al. Infiltrating urothelial carcinoma. In: World health organization classification of tumours. Pathology and genetics of tumours of the urinary system and male genital organs, Lyon: IARC Press, 2004:93-109.

4. Sahin AA, Myhre M, Ro JY, et al. Plasmacytoid transitional cell carcinoma. Report of a case with initial presentation mimicking multiple myeloma. Acta Cytol 1991;35:277-80.

5. Zukerberg LR, Harris NL, Young RH. Carcinomas of the urinary bladder simulating malignant lymphoma. A report of five cases. Am I Surg Pathol 1991;15:569-76. https:/doi.org/10.1097/00000478199106000-00005

6. Lopez-Beltran A, Requena MJ, Montironi R, et al. Plasmacytoid urothelial carcinoma of the bladder. Hum Pathol 2009;40:1023-8. https:/doi.org/10.1016/i.humpath.2009.01.001

7. Mai KT, Park PC, Yazdi HM, et al. Plasmacytoid urothelial carcinoma of the urinary bladder: Report of seven new cases. Eur Urol 2006;50:1111-4. https:/doi.org/10.1016/i.eururo.2005.12.047

8. Raspollini MR, Sardi I, Giunti L, et al. Plasmacytoid urothelial carcinoma of the urinary bladder: Clinicopathologic, immunohistochemical, ultrastructural, and molecular analysis of a case series. Hum Pathol 2011;42:1149-58. https:/doi.org/10.1016/i.humpath.2010.11.011 
9. Sato K, Ueda Y, Kawamura K, et al. Plasmacytoid urothelial carcinoma of the urinary bladder: A case report and immunohistochemical study. Pathol Res Pract 2009;205:189-94. https:/doi.org/10.1016/i. prp.2008.09.004

10. Dayyani F, Czerniak BA, Sircar K, et al. Plasmacytoid urothelial carcinoma, a chemosensitive cancer with poor prognosis, and peritoneal carcinomatosis. J Urol 2013;189:1656-61. htrps:/doi.org/10.1016/i. juro.2012.11.084

11. Ricardo-Gonzalez RR, Nguyen M, Gokden N, et al. Plasmacytoid carcinoma of the bladder: A urothelial carcinoma variant with a predilection for intraperitoneal spread. J Urol 2012;187:852-5. https:/doi.org/10.1016/i.juro.2011.10.145

12. Keck $B$, Stoehr $R$, Wach $S$, et al. The plasmacytoid carcinoma of the bladder — rare variant of aggressive urothelial carcinoma. Int J Cancer 2011;129:346-54. https:/doi.org/10.1002/iic.25700

13. Mitsogiannis $I C$, loannou $M G$, Sinani $C D$, et al. Plasmacytoid transitional cell carcinoma of the urinary bladder. Urology 2005;66:194. https:/doi.org/10.1016/i.urology.2005.01.023

14. Nigwekar P, Tamboli P, Amin MB, et al. Plasmacytoid urothelial carcinoma: Detailed analysis of morphology with clinicopathologic correlation in 17 cases. Am J Surg Pathol 2009;33:417-24. https:/doi.org/10.1097/PAS.0b013e318186c45e

15. Kaimakliotis HZ, Monn MF, Cheng L, et al. Plasmacytoid bladder cancer: Variant histology with aggressive behaviour and a new mode of invasion along fascial planes. Urology 2014;83:1112-6. https:/doi.org/10.1016/i.urology.2013.12.035

16. Kassouf W, Traboulsi SL, Kulkarni GS, et al. CUA guidelines on the management of non-muscle invasive bladder cancer. Can Urol Assoc J 2015;9:E690-704. hittps:/doi.org/10.5489/cuai.3320

17. Keck B, Wach S, Stoehr R, et al. Plasmacytoid variant of bladder cancer defines patients with poor prognosis if treated with cystectomy and adjuvant cisplatin-based chemotherapy. BMC Cancer 2013;13:71. https:/doi.org/10.1186/1471-2407-13-71

18. $\operatorname{Kim} B$, Kim G, Song B, et al. HER2 protein overexpression and gene amplification in plasmacytoid urothelia carcinoma of the urinary bladder. Dis Markers 2016;2016:6.

19. Raman SP, Fishman EK. Bladder malignancies on CT: The underrated role of CT in diagnosis. Am J Roentgenol 2014;203:347-54. https:/doi.org/10.2214/AJR.13.12021

20. Wang L, Wong Y, Ng K, et al. Tumour characteristics of urothelial carcinoma on multidetector computerized tomography urography. J Urol 2010;183:2154-60. https:/doi.org/10.1016/i.juro.2010.02.028

21. Molen AJ, Cowan NC, Mueller-Lisse UG, et al. CT urography: Definition, indications and techniques. A guideline for clinical practice. Eur Radiol 2008; 18:4-17. https:/doi.org/10.1007/s00330-007-0792-x

22. Kobayashi S, Koga F, Yoshida $S$, et al. Diagnostic performance of diffusion-weighted magnetic resonance imaging in bladder cancer: Potential utility of apparent diffusion coefficient values as a biomarker to predict clinical aggressiveness. Eur Radiol 2011;21:2178-86. https:/doi.org/10.1007/s00330-011-2174-7

23. Kundra V, Silverman PM. Imaging in the diagnosis, staging, and followup of cancer of the urinary bladder. Am J Roentgenol 2003;180:1045-54. htrps:/doi.org/10.2214/air.180.4.1801045

24. Vikram R, Sandler CM, $\mathrm{Ng}$ CS. Imaging and staging of transitional cell carcinoma: Part 1, lower urinary tract. Am J Roentgenol 2009;192:1481-7. https:/doi.org/10.2214/AJR.08.1318

25. El-Assmy A, Abou-El-Ghar M, Mosbah A, et al. Bladder tumour staging: Comparison of diffusion- and T2-weighted MR imaging. Eur Radiol 2009;19:1575-81. https:/doi.org/10.1007/s00330-009-1340-7

26. Rajesh A, Sokhi HK, Fung R, et al. Bladder cancer: Evaluation of staging accuracy using dynamic MRI. Clin Radiol 2011;66:1140-5. https:/doi.org/10.1016/i.crad.2011.05.019

27. Dotan ZA, Kavanagh $K$, Yossepowitch 0 , et al. Positive surgical margins in soft tissue following radical cystectomy for bladder cancer and cancer specific survival. J Urol 2007;178:2308-12. https:/doi.org/10.1016/i.juro.2007.08.023

28. Herr HW, Faulkner JR, Grossman HB, et al. Surgical factors influence bladder cancer outcomes: A cooperative group report. J Clin Oncol 2004;22:2781-9. htrps:/doi.org/10.1200/JC0.2004.11.024
29. Mitra AP, Quinn DI, Dorff TB, et al. Factors influencing post-recurrence survival in bladder cancer following radical cystectomy. BJU Int 2012;109:846-54. https:/doi.org/10.1111/j.1464-410X.2011.10455.x

30. Honma I, Masumori N, Sato E, et al. Local recurrence after radical cystectomy for invasive bladder cancer: An analysis of predictive factors. Urology 2004;64:744-8. https:/doi.org/10.1016/i.urology.2004.05.003

31. Turkbey B, Basaran C, Karcaaltincaba $M$, et al. Peritoneal carcinomatosis in urinary bladder cancer. Clin Imaging 2008;32:192-5. https:/doi.org/10.1016/i.clinimag.2007.10.024

32. Shinagare AB, Ramaiya NH, Jagannathan JP, et al. Metastatic pattern of bladder cancer: Correlation with the characteristics of the primary tumour. Am J Roentgenol 2011;196:117-22. https:/doi.org/10.2214/ AJR. 10.5036

Correspondence: Dr. Nicola Schieda, Department of Medical Imaging, The Ottawa Hospital, University of Ottawa, Ottawa, ON, Canada; nschieda@toh.ca

\begin{tabular}{lc}
\hline $\begin{array}{l}\text { Appendix A. CT protocols for baseline abdominopelvic } \\
\text { imaging studies }\end{array}$ & $\mathbf{n = 2 2}$ \\
\hline Imaging protocol & \\
\hline Single-phase & 3 \\
NECT & 7 \\
PVP & 2 \\
Split-bolus CT urography* & 7 \\
Biphasic & 2 \\
NECT + split-bolus CT urography & \\
PVP + delayed phase & \\
Triphasic & 1 \\
NECT + corticomedullary, nephrographical phases & \\
\hline
\end{tabular}

${ }^{*}$ Split-bolus CT urography: combined nephrographical/urographical phase; ${ }^{\dagger}$ delayed phase: urographical phase. CT: computed tomography; NECT: non-enhanced CT; PVP: portal venous phase.

\begin{tabular}{|c|c|}
\hline \multicolumn{2}{|l|}{$\begin{array}{l}\text { Appendix B. MRI protocol for baseline abdominopelvic } \\
\text { imaging studies }\end{array}$} \\
\hline Imaging protocol & $\mathrm{n}=6$ \\
\hline Large FOV localizer (bSSFP or T2W SSFSE imaging) & 6 \\
\hline Axial, coronal, and sagittal small FOV T2W FSE & 6 \\
\hline $\begin{array}{l}\text { Sagittal T1W 3D FS GRE before and after administration } \\
\text { of extracellular gadolinium, dynamic or fixed delay } \\
\text { acquisition }\end{array}$ & 6 \\
\hline Diffusion weighted imaging (DWI) & 2 \\
\hline \multicolumn{2}{|c|}{$\begin{array}{l}\text { bSSFP: balanced steady state free precession; FOV: field of view; FS: fat-suppressed; } \\
\text { GRE: gradient recalled echo; SSFSE: single-shot fast spin echo; T2W: T2-weighted; 3D: } \\
\text { 3-dimensional. }\end{array}$} \\
\hline
\end{tabular}

